\title{
Light induced electropolymerization of poly(3,4-ethylenedioxythiophene) on niobium oxide
}

\author{
F. Di Franco, P. Bocchetta, M. Santamaria*, F. Di Quarto \\ Dipartimento di Ingegneria chimica dei Processi e dei Materiali, Università degli Studi di Palermo, Viale delle Scienze, 90128 Palermo, Italy
}

\section{A R T I C L E I N F O}

\section{Article history:}

Received 20 July 2010

Received in revised form

11 September 2010

Accepted 18 September 2010

Available online 25 September 2010

\section{Keywords:}

Niobium oxide

PEDOT

Photoelectrochemistry

Band gap

\begin{abstract}
A B S T R A C T
The photoelectrochemical polymerization of poly(3,4-ethylenedioxythiophene), PEDOT, was successfully realized on anodic film grown to $50 \mathrm{~V}$ on magnetron sputtered niobium. Photocurrent Spectroscopy was employed to study the optical properties of $\mathrm{Nb} / \mathrm{Nb}_{2} \mathrm{O}_{5} / \mathrm{PEDOT} /$ electrolyte interface in a large range of potential, and to get an estimate of the band gap and flat band potential of both the oxide and the polymer. Scanning Electron Microscopy was used to study the morphology of PEDOT. Both the optical and morphological features of the photoelectrochemically grown polymer were compared with those showed by PEDOT electropolymerized on gold conducting substrate.
\end{abstract}

(c) 2010 Elsevier Ltd. All rights reserved.

\section{Introduction}

A conventional electrolytic capacitor consists of a valve metal (e.g. aluminium or tantalum), covered by an anodic film, the dielectric, in direct contact with an electrolyte, the true counter electrode, which in turn is connected to a current collector, usually made by the same valve metal. In the so called "solid state" tantalum electrolytic capacitors, the liquid electrolyte has been substituted by a solid ionic conductor $\left(\beta-\mathrm{MnO}_{2}\right)$, whose conductivity is one of the drawbacks of the device. Thus, it has been recently proposed in the literature to replace manganese dioxide with a conductive polymer, which in principle can show a conductivity comparable to that of a metal [1].

Since 1999 [2], poly(3,4-ethylenedioxythiophene) has been successfully proposed as suitable conducting polymer for tantalum solid capacitor due to its excellent environmental stability. Usually, PEDOT is synthesized chemically in aqueous medium in the presence of an oxidizer agent (i.e. ferric sulphate). However, this method can leave strongly acidic oxidant on the polymer chains, which can cause the degradation of the dielectric, thus the electropolymerization should be safer for preparing PEDOT to be employed as counter electrode in solid state capacitors [3]. To overcome the difficulty of performing such electrochemical process on dielectrics, we recently proposed a photoelectrochemical method [4] to grow polypyrrole on tantalum oxide. Such method has been successfully

\footnotetext{
* Corresponding author.

E-mail address: santamaria@dicpm.unipa.it (M. Santamaria).
}

employed to synthesize PEDOT on $\mathrm{Ta}_{2} \mathrm{O}_{5}$ [3] and on $\mathrm{Ti}-\mathrm{Zr}$ mixed oxides [5].

Few examples of photoelectrochemical polymerization on semiconductors have been reported in the literature for protection against corrosion of the materials [6] or as reaction initiators [7].

On the other hand, high cost and limited availability of tantalum natural resources are pushing capacitor technologists to replace Ta with $\mathrm{Nb}$, which is more abundant in earth crust and whose oxide, i.e. $\mathrm{Nb}_{2} \mathrm{O}_{5}$, has a permittivity higher than that measured for $\mathrm{Ta}_{2} \mathrm{O}_{5}$. However, as far as we know, only a paper has been published reporting on the chemical polymerization of pyrrole and aniline on $\mathrm{Nb}_{2} \mathrm{O}_{5}$ to be employed in electrolytic capacitors [8].

In this work we report on the photoelectrochemical polymerization of PEDOT on anodic film grown to $50 \mathrm{~V}$ on magnetron sputtered niobium. Photocurrent Spectroscopy was employed to study the optical properties of $\mathrm{Nb} / \mathrm{Nb}_{2} \mathrm{O}_{5} / \mathrm{PEDOT} /$ electrolyte interface in a large range of potential, while Scanning Electron Microscopy was used to get information of the morphology of the polymers. The characteristic features of the photoelectrochemically grown polymer were also compared with those showed by PEDOT electropolymerized on gold conducting substrate.

\section{Experimental}

The electropolymerization was performed on gold electrode (rod $4 \mathrm{~mm}$ diameter or foils) in $0.1 \mathrm{M} \mathrm{LiClO}_{4}$ propylene carbonate (PC, 99.8 Sigma-Aldrich) with $0.1 \mathrm{M}$ 3,4-ethylenedioxythiophene (EDOT). 
Niobium films $300 \mathrm{~nm}$ thick were magnetron sputtered onto a glass substrate using a $99.9 \%$ pure niobium target of $100 \mathrm{~mm}$ diameter. The deposited niobium had a body-centred cubic structure with a 110 preferred orientation. These films were anodized at a constant current density of $50 \mathrm{~A} \mathrm{~m}^{-2}$ in $0.1 \mathrm{~mol} \mathrm{dm}^{-3}$ ammonium pentaborate at $293 \mathrm{~K}$, the potential being kept constant for $1 \mathrm{~h}$ at the final cell voltage of $50 \mathrm{~V}[9,10]$. The polymerization was performed in $0.1 \mathrm{M} \mathrm{LiClO}_{4}$ propylene carbonate (PC, 99.8 Sigma-Aldrich) with $0.04 \mathrm{M}$ 3,4-ethylenedioxythiophene (EDOT) concentration under irradiation $(\lambda=310 \mathrm{~nm})$.

The electrochemical and photoelectrochemical experiments in propylene carbonate were carried out using a three electrodes cell with a Pt wire as counter electrode and an aqueous silver/silver chloride $(\mathrm{Ag} / \mathrm{AgCl}: 0.197 \mathrm{~V} / \mathrm{HNE})$ as reference electrode, separated by a fritt glass from the working electrode. The liquid junction potential between aqueous and non-aqueous solution has been checked to be negligible.

The PEDOT morphology was investigated using a Philips XL30 ESEM scanning electron microscope. Some of the PEDOT films were detached from the substrate with copper conducting adhesive in order to allow the view of electrode side polymer and of its cross section. The $\mathrm{Nb}_{2} \mathrm{O}_{5} / \mathrm{PEDOT} /$ electrolyte junction was investigated by Photocurrent Spectroscopy (PCS). The photoelectrochemical setup is described elsewhere [11]. Briefly, a $450 \mathrm{~W}$ UV-visible xenon lamp, coupled with a monochromator, irradiates the specimen through a quartz window in the anodizing cell. A two-phase lock-in amplifier, with a mechanical chopper (chopping frequency $=13 \mathrm{~Hz}$ ), enables separation of the photocurrent from total current.

\section{Results and discussion}

\subsection{Electrodeposition and characterization of PEDOT on gold}

In Fig. 1 we report the current density vs time curve recorded by polarizing a gold electrode at $1.2 \mathrm{~V}(\mathrm{Ag} / \mathrm{AgCl})$ in $0.1 \mathrm{M} \mathrm{LiClO}_{4}$ PC (propylene carbonate) solution containing 0.1 M EDOT (3,4ethylenedioxythiophene). This potential value is more anodic than the oxidation potential of EDOT/EDOT ${ }^{+}$couple $\left(E_{o x}=1.1 \mathrm{~V} \mathrm{vs}\right.$ $\mathrm{Ag} / \mathrm{AgCl}$ in $\mathrm{PC}$, according to Ref. [12]) but is lower than oxidation potential of propylene carbonate $\left(E_{o x}=1.8 \mathrm{~V}\right.$ vs $\mathrm{Ag} / \mathrm{AgCl}$, according to Ref. [13]). Thus, we can attribute the measured current to the oxidation of monomer and to its subsequent polymerization, according to the following processes:

$n \mathrm{EDOT}(\mathrm{sol}) \rightarrow n \mathrm{EDOT}^{+\bullet}+n \mathrm{e}^{-}$

$n \mathrm{EDOT}^{+} \cdot+z \mathrm{ClO}_{4}^{-} \rightarrow(n-z) \mathrm{H}^{+}+\left[\left(\mathrm{EDOT}_{n}\right)^{z+}\left(\mathrm{ClO}_{4}^{-}\right)_{z}\right]$

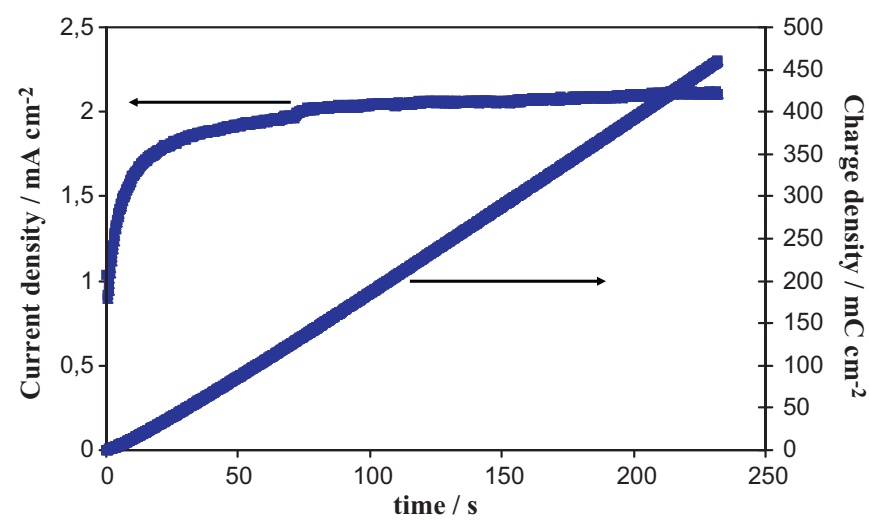

Fig. 1. Current density and charge density vs time recorded by polarizing the electrode (gold rod) at $1.2 \mathrm{~V}(\mathrm{Ag} / \mathrm{AgCl})$ in $0.1 \mathrm{M} \mathrm{LiClO}_{4}$ propylene carbonate solution containing $0.1 \mathrm{M}$ EDOT. where $n \mathrm{e}^{-}$are $n$-electrons, $n$ EDOT are $n$-monomers of ethylene dioxythiophene, $n$ EDOT $^{+}$are $n$-radical cations of EDOT and $z$ is a measure of the doping level of polymer. In Eqs. (1a) and (1b), usually reported for the electropolymerization of pyrrole and thiophene on conducting substrates [14], the formation of EDOT radical cations is the preliminary step toward the polymer growth and its simultaneous doping according to Eq. (1b)[15]. The curve of Fig. 1 is analogous to those reported in the literature for the electropolymerization of 3-4 ethylene dioxythiophene performed in very similar experimental conditions $[16,17]$. After a very short induction time $(\sim 0.4 \mathrm{~s})$, during which we suppose that the oxidation of monomers brings to the formation of soluble oligomers [18], the nucleation of the polymer on the gold surface begins with the subsequent thickening of the PEDOT layer. A careful SEM analysis of polymer cross sections (see Fig. 2a) allowed to estimate an average thickness of $\sim 1.4 \mu \mathrm{m}$ for PEDOT after circulation of $460 \mathrm{mC} \mathrm{cm}^{-2}$, corresponding to a polarization time of $230 \mathrm{~s}$ (see Fig. 1). If we assume for PEDOT a density of $1.5 \mathrm{~g} \mathrm{~cm}^{-3}$ [3], it is possible to estimate an electropolymerization efficiency of $70 \%$ by comparing the experimental thickness to that estimated according to Faraday law:

$d=\frac{\mathrm{PM}}{n F \rho} q$

where PM is the monomer molecular weight (i.e. $142 \mathrm{~g} \mathrm{~mol}^{-1}$ ), $\rho$ is the polymer density, $q$ is the charged per unit surface in $\mathrm{C} \mathrm{cm}^{-2}$ and $n$ is assumed 2.25, since the polymerization of EDOT is assumed to involve two electrons while the partial oxidation of already grown film (i.e. doping) is assumed to consume the excess 0.25 charge [18]. An efficiency lower than $100 \%$ can be explained by the occurrence of coupling reactions between radicals bringing to formation of oligomers soluble in the electrolyte (not only during the induction time), the occurrence of doping process of already grown polymer, which reduces the charge effectively employed for the polymer thickening.

In Fig. 2b and $c$ we report the SEM micrographs relating to the morphology of the polymer surface after two different circulated charges. By comparing the pictures, it comes out that PEDOT becomes more porous with increasing the circulated charge. The morphology is different with respect to that shown by PEDOT prepared in water [19] and in methyl benzoate solutions [20], but very similar to that shown by the film electropolymerized in propylene carbonate in spite of different supporting electrolyte and bath temperature [20]. This finding indicates a strong influence of the solvent on the morphology of the layer. A different morphology is shown by the polymer-electrode side (see Fig. $2 \mathrm{~d}$ ), which appears very compact. This is in agreement with a porosity increasing with increasing circulated charge.

In Fig. 3 we report the cyclic voltammetry recorded by sweeping the potential of the gold/polymer electrode at $10 \mathrm{mV} \mathrm{s}^{-1}$ in a $0.1 \mathrm{M}$ $\mathrm{LiClO}_{4}$ in PC. During the forward scan an anodic peak is present at $0.5 \mathrm{~V}(\mathrm{Ag} / \mathrm{AgCl})$, which can be attributed to the doping process of polymer chains, while in the reverse scan two cathodic peaks, at -0.2 and $-0.6 \mathrm{~V}(\mathrm{Ag} / \mathrm{AgCl})$, correspond to the de-doping process [12]. In the voltage range between -2 and $-0.6 \mathrm{~V}(\mathrm{Ag} / \mathrm{AgCl})$ the polymeric film is stable and its electronic structure is not modified.

The grown polymer was not photoactive at the formation voltage, whilst cathodic photocurrent was observed under cathodic polarization. In Fig. 4a we report the photocurrent vs wavelength curve at constant potential (photocurrent spectrum) recorded by polarizing the polymeric film of Fig. 1 at $-2 \mathrm{~V}(\mathrm{Ag} / \mathrm{AgCl})$ in $0.1 \mathrm{M}$ $\mathrm{LiClO}_{4} \mathrm{PC}$. At this potential the photocurrent is cathodic as expected due to the p-type semiconductor nature of the polymer. From the photocurrent spectra for photon energy in the vicinity of the band gap, it is possible to estimate the optical band gap value of the 
(a)

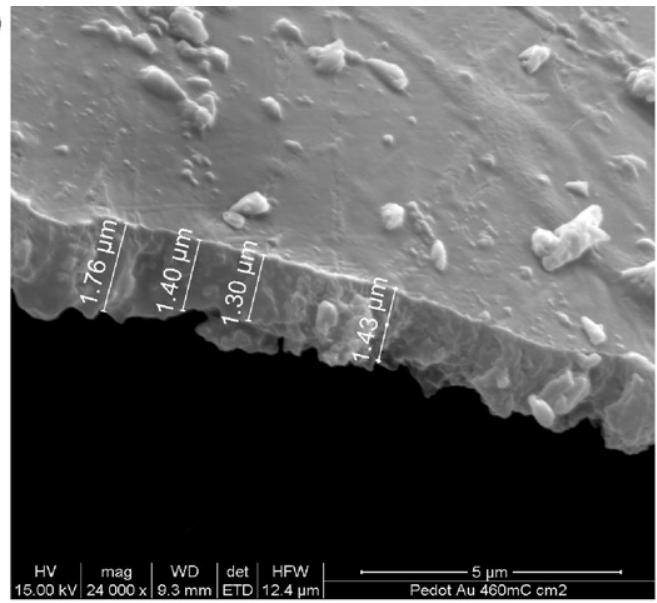

(c)

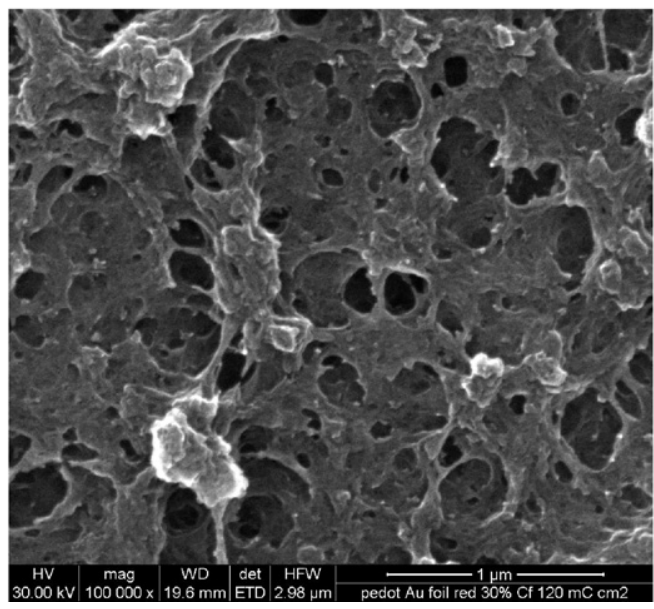

(b)

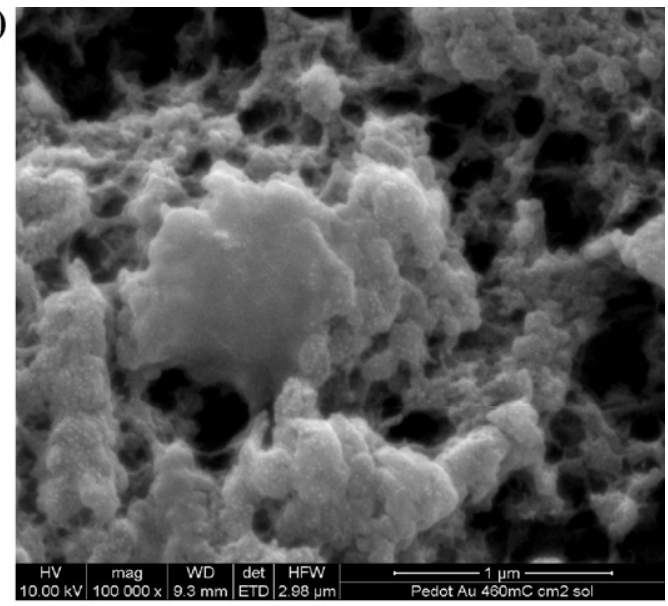

(d)

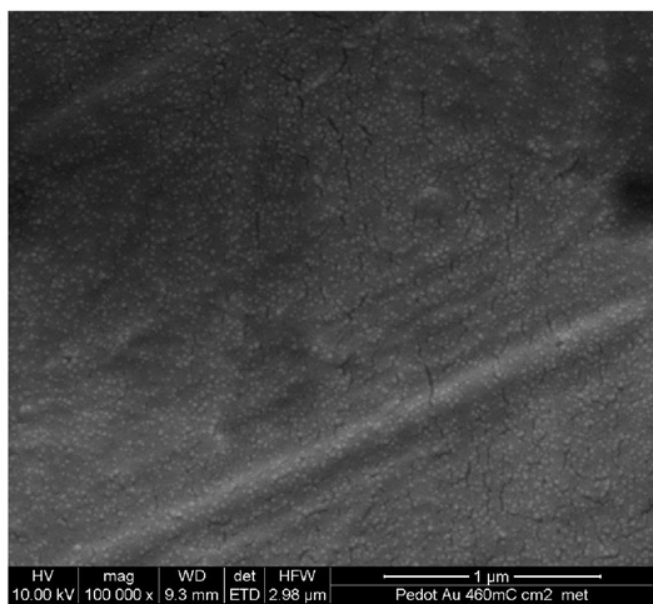

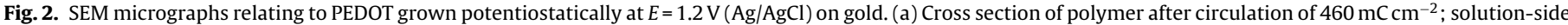
surface morphologies after circulation of (b) $460 \mathrm{mC} \mathrm{cm}^{-2}$, (c) $120 \mathrm{mC} \mathrm{cm}^{-2}$, and (d) electrode side morphology.

polymer according to the following equation:

$\left(I_{p h} h v\right)^{n} \propto\left(h v-E_{g}^{o p t}\right)$

where $I_{p h}$ is the photocurrent yield, assumed proportional to the light absorption coefficient, $h v$ is the photon energy, $E_{g}^{o p t}$ the optical band gap and an $n$ value equal to 0.5 has been assumed for indirect optical transitions and $n$ value equal to 2 has been assumed for

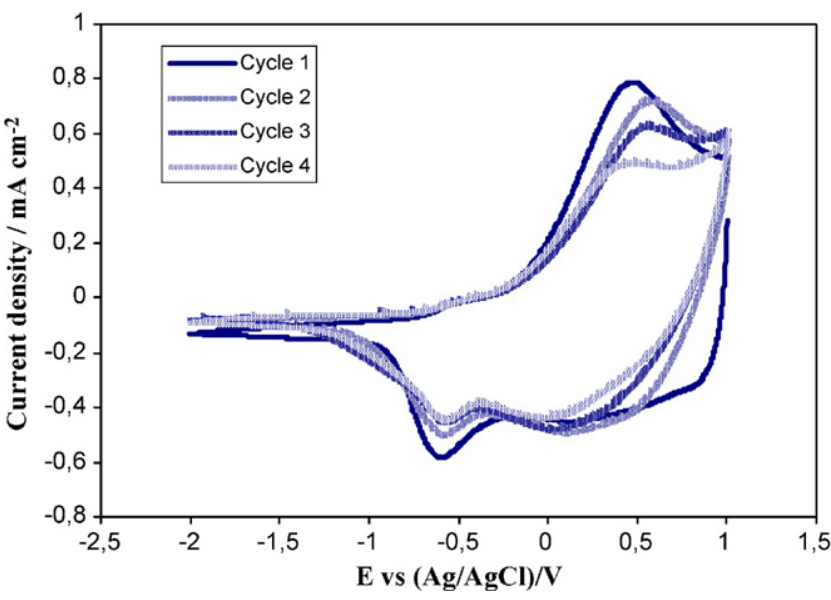

Fig. 3. Cyclic voltammetry relating to PEDOT film electrochemically grown after circulation of $460 \mathrm{mC} \mathrm{cm}^{-2}$ on gold electrode, recorded at $10 \mathrm{mV} \mathrm{s}^{-1}$ in $0.1 \mathrm{M} \mathrm{LiClO}_{4}$ propylene carbonate solution. direct optical transitions [21]. As shown in Fig. 4b and c, a direct optical transition at $1.74 \mathrm{eV}$ and an indirect one at around $1.58 \mathrm{eV}$ were determined, both values being very close to those reported in previous works for PEDOT [21,22]. Moreover, the direct optical band gap of PEDOT agrees quite well with the theoretically estimated HOMO-LUMO gap (1.68-1.83 eV) of oligomers extrapolated to infinite chain length [23]. The lower band gap measured in the hypothesis of indirect (or non-direct if amorphous) optical transitions could be attributed to the formation, near the valence band of PEDOT, of a band of defects (polaron and/or bipolaron) during the de-doping process [24].

In Fig. 5 we report the photocurrent vs potential curve (photocharacteristic) recorded by irradiating the polymer surface at $485 \mathrm{~nm}$ in $0.1 \mathrm{M} \mathrm{LiClO}_{4} \mathrm{PC}$ electrolyte. By moving the polarizing voltage toward the anodic direction at $10 \mathrm{mV} \mathrm{s}^{-1}$, the photocurrent decreases as typical of p-type semiconductors. It is interesting to mention that the photocurrent goes to zero at $-0.55 \mathrm{~V}(\mathrm{Ag} / \mathrm{AgCl})$, that can be assumed as a rough estimate of the flat band potential in propylene carbonate. The occurrence of doping process at potential very close or more anodic with respect to this value (see Fig. 3) induces the metallization of the polymer and hinders the possibility to detect any photocurrent.

\subsection{Characteristic energy levels location of $\mathrm{Nb}_{2} \mathrm{O}_{5} / \mathrm{PC}$ interface}

In Fig. 6a we report the photocurrent spectrum relating to the $50 \mathrm{~V}$ anodic film on $\mathrm{Nb}$, recorded by polarizing the electrode at $8 \mathrm{~V}$ vs $(\mathrm{Ag} / \mathrm{AgCl})$ in $0.1 \mathrm{M} \mathrm{LiClO}_{4} \mathrm{PC}$ electrolyte. According to Eq. (3), a 

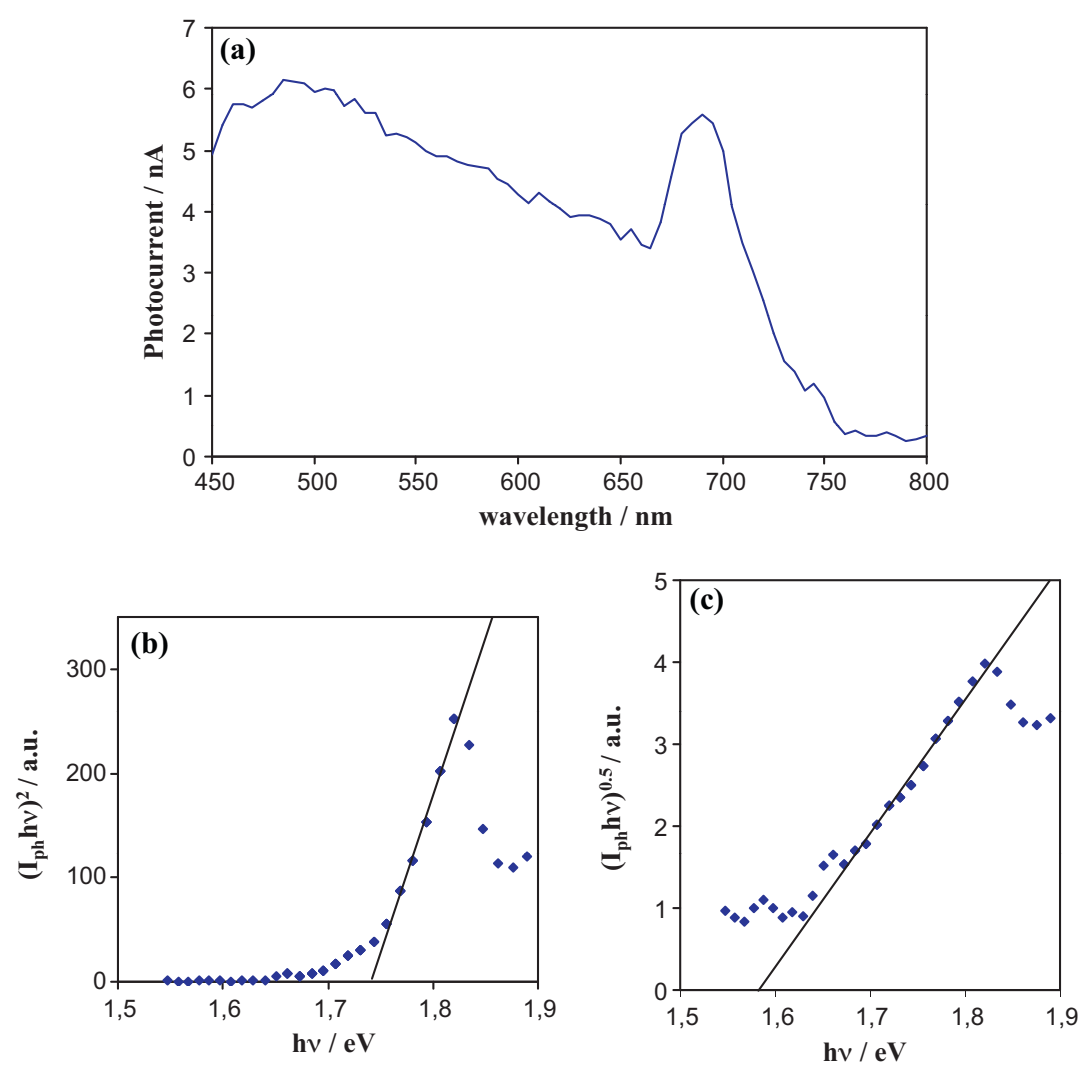

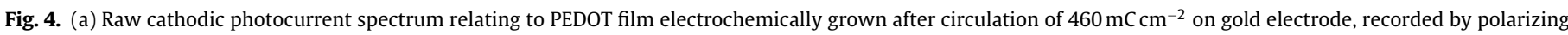
the $\mathrm{Au} /$ Pedot interface in $0.1 \mathrm{M} \mathrm{LiClO}_{4}$ propylene carbonate at $E=-2 \mathrm{~V}(\mathrm{Ag} / \mathrm{AgCl})$. Band gap estimate by assuming (b) direct and (c) non-direct optical transitions.

non-direct band gap value of $3.42 \mathrm{eV}$ (see Fig. 6b) can be estimated, which is very close to that previously estimated in aqueous solution for films grown on Niobium in the same conditions [10]. The location of characteristic energy levels of the junction (flat band potential, $E_{f b}$, conduction and valence band edges) was carried out by assuming the zero photocurrent potential, $E^{*}$, derived from the photocurrent vs potential plot at $320 \mathrm{~nm}$ (Fig. 7), as a proxy of the flat band potential $\left(E_{f b}=-0.5 \mathrm{vs} \mathrm{Ag} / \mathrm{AgCl}\right)$ of the oxide/organic electrolyte interface. If we assume that the organic electrolyte is equivalent to an aqueous solution at the niobium oxide isoelectric point $\left(\mathrm{pH}_{\mathrm{pzc}}\right)$, this value compares well with the $E_{f b}$ reported in Ref. [10] estimated in strongly acidic electrolyte, according to the

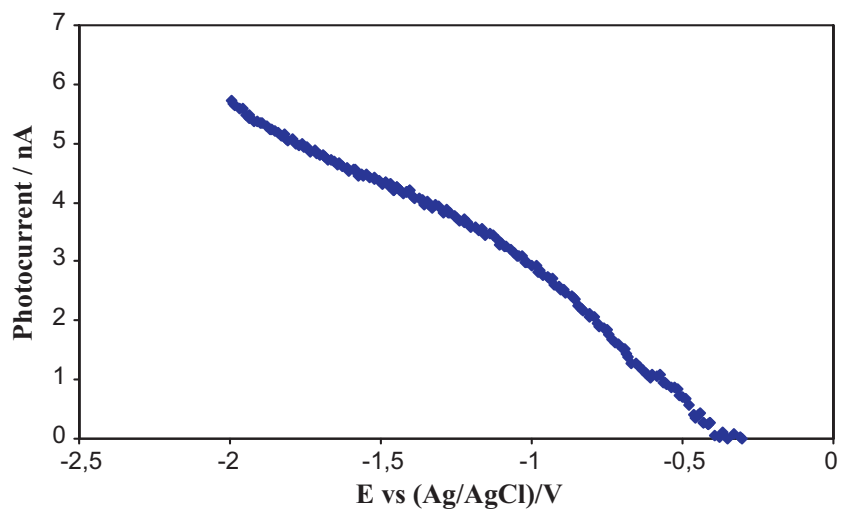

Fig. 5. Photocurrent vs potential curve relating to PEDOT film electrochemically grown after circulation of $460 \mathrm{mC} \mathrm{cm}^{-2}$ on gold electrode, recorded by irradiating the $\mathrm{Au} / \mathrm{PEDOT}$ interface in $0.1 \mathrm{M} \mathrm{LiClO}_{4}$ propylene carbonate at $485 \mathrm{~nm}$ (light intensity is $80 \mathrm{~mW} \mathrm{~cm}^{-2}$ ) following equation:

$E_{\mathrm{fb}}=E_{\mathrm{fb} \mathrm{pH}_{\mathrm{pzc}}}-0.059\left(\mathrm{pH}-\mathrm{pH}_{\mathrm{pzc}}\right)$

where $\mathrm{pH}_{\mathrm{pzc}}=4.1$ for $\mathrm{Nb}_{2} \mathrm{O}_{5}$ [25]. From such estimate, after location of the conduction band mobility edge of oxide around $0.37 \mathrm{eV}$ above $E_{f b}$ [10], the energy level of the valence band edge of anodic $\mathrm{Nb}_{2} \mathrm{O}_{5}$ was located at around $2.55 \mathrm{eV}$ below the reference electrode, i.e. at about $0.75 \mathrm{eV}$ below the oxidation potential of propylene carbonate $\left(E_{o x}=1.8 \mathrm{~V}\right.$ vs $\mathrm{Ag} / \mathrm{AgCl}$, according to Ref. [13]). This estimate of energy levels of the junction agrees with the observed anodic photocurrent, in the absence of monomer, attributed to the photoelectrochemical oxidation of the solvent. In Fig. 8 we show the schematic picture of the energetic levels at the oxide/organic interface.

\subsection{Photoelectrodeposition and characterization of PEDOT on $\mathrm{Nb}_{2} \mathrm{O}_{5}$}

In Fig. 9a we report the current vs time curve recorded under irradiation $(\lambda=320 \mathrm{~nm})$ by polarizing $\mathrm{Nb}_{2} \mathrm{O}_{5}$ at $U_{E}=8 \mathrm{~V}(\mathrm{Ag} / \mathrm{AgCl})$, in $0.1 \mathrm{M} \mathrm{LiClO}_{4} \mathrm{PC}$ solution containing $0.04 \mathrm{M}$ EDOT. By irradiating the anodic oxide surface with photon energy higher than the band gap of the anodic film $(\lambda=320 \mathrm{~nm})$, the growth of polymer occurred according to the following processes:

$$
\begin{aligned}
& \mathrm{Nb}_{2} \mathrm{O}_{5}+h v \rightarrow \mathrm{e}^{-} \mathrm{CB}+h^{+} \mathrm{VB} \\
& n \mathrm{EDOT}^{(\mathrm{sol})}+n h^{+}{ }_{\mathrm{VB}} \rightarrow n \mathrm{EDOT}^{+} \bullet \\
& n \mathrm{EDOT}^{+} \cdot+z \mathrm{ClO}_{4}^{-} \rightarrow(n-z) \mathrm{H}^{+}+\left[\left(\mathrm{EDOT}_{n}\right)^{z+}\left(\mathrm{ClO}_{4}^{-}\right)_{z}\right]
\end{aligned}
$$

where $e^{-}$Св is an electron in the conduction band of oxide and $h^{+} \mathrm{VB}$ is a hole in the valence band of oxide. Eqs. (5b) and (5c) are similar to Eq. (1a) and (1b). 

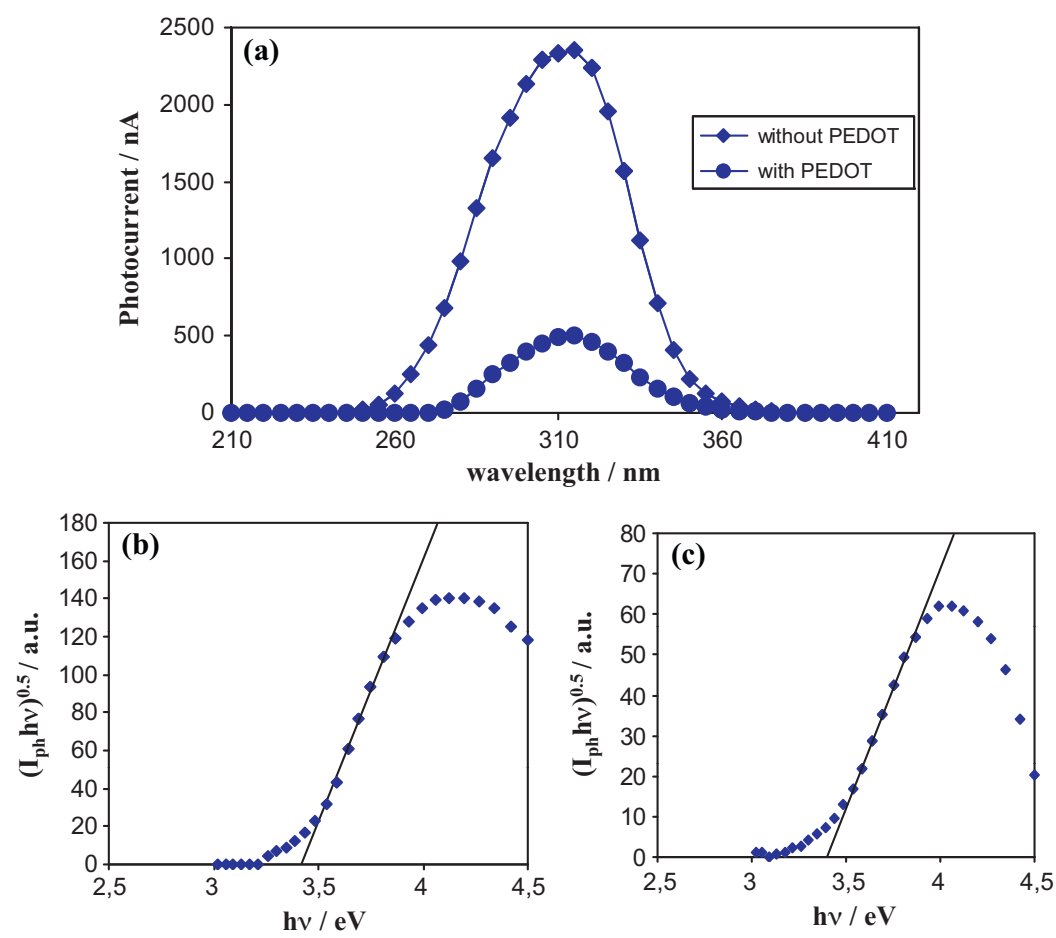

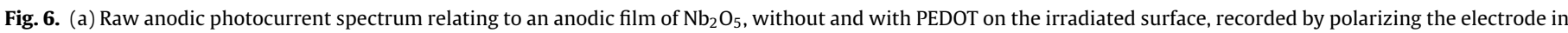
$0.1 \mathrm{M} \mathrm{LiClO}_{4}$ propylene carbonate at $3 \mathrm{~V}(\mathrm{Ag} / \mathrm{AgCl}) .\left(I_{p h} h v\right)^{0.5} \mathrm{vs} h v$ plots relating to the oxide (b) without and (c) with PEDOT.

According to the energetics of the oxide/electrolyte interface of Fig. 8, it is evident that both the oxidation of EDOT and of PC are thermodynamically possible. The occurrence of photoelectrochemical polymerization was confirmed by SEM analysis of the samples at short times or by direct visual inspection for longer photodeposition times.

As shown in Fig. 9b, during the early stages of photoelectrodeposition $I_{p h}$ decreases almost exponentially as a function of the circulated charge, i.e. of polymer layer thickness. This behaviour can be explained by the reduced number of photons reaching the oxide surface with increasing polymer thickness. If we assume that the growing polymer behaves like an absorbing metallic layer with a constant light absorption coefficient, $\alpha$, it is possible to fit the experimental curve according to the following equation:

$$
I_{p h}\left(q_{p h}\right)=I_{p h}(0) \exp \left(-4.9 \times 10^{-4} \alpha \operatorname{PEDOT} q_{p h}\right)
$$

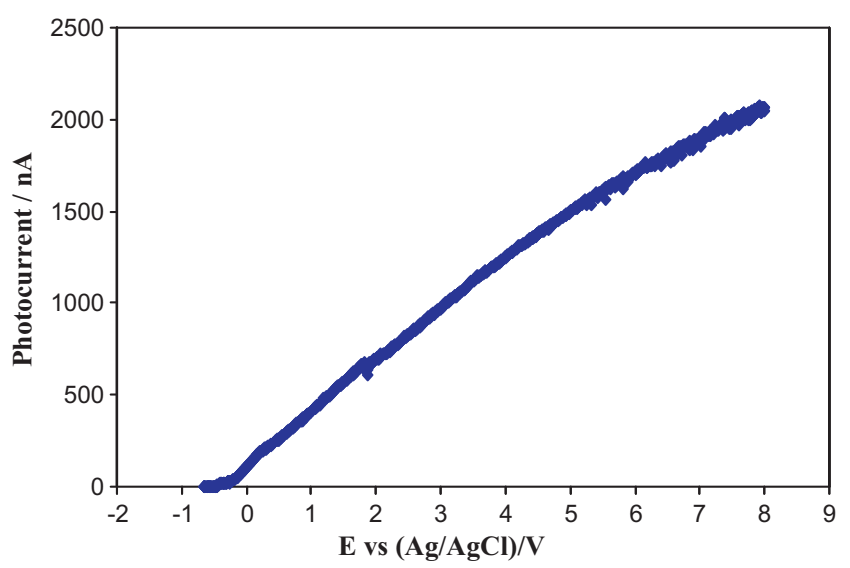

Fig. 7. Photocurrent vs potential curve relating to an anodic film of $\mathrm{Nb}_{2} \mathrm{O}_{5}$, recorded by irradiating the electrode in $0.1 \mathrm{M} \mathrm{LiClO}_{4}$ propylene carbonate at $320 \mathrm{~nm}$. where $I_{p h}$ is the photocurrent, a the light absorption coefficient of the growing polymer and $q_{p h}$ the photocirculated charge per unit area. From the initial slope of the $I_{p h}$ vs $q_{p h}$ curve, a light absorption coefficient of $\sim 4.810^{4} \mathrm{~cm}^{-1}$ can be estimated by Eq. (6), which is in agreement with the values reported in the literature and slightly lower than that estimated with the same procedure during the early stage of electropolymerization of polypyrrole on $\mathrm{Ta}_{2} \mathrm{O}_{5}$ but under irradiation of monochromatic light at shorter wavelength [4]. At longer photoelectropolymerization time a deviation from the linear slope is observed, that can be explained by considering that the photo oxidation occurs on a surface progressively larger with respect to the initial one owing to a spot light smaller that the whole exposed surface. A possible variation in the efficiency of the photo oxidation of EDOT cannot be excluded although we have no experimental evidences supporting this hypothesis.

A morphological study of PEDOT photoelectrochemically grown on $\mathrm{Nb}_{2} \mathrm{O}_{5}$ electrodes was carried out. In Fig. 10 we report the SEM micrographs of solution-side and oxide-side PEDOT grown on niobium oxide. The morphologies in both cases are really different with respect to those evidenced for electrochemically grown polymer (see Fig. 2). The solution-side micrograph (Fig. 10a) reveals that the surface of the polymer is slightly corrugated, with the presence of compact and flat regions delimited by interconnected ridges of polymeric material, missing for electrochemically grown polymer even at higher circulated charges. Analogous morphology has been reported for poly(3-hexylthiophene) grown by spinning coating on $\mathrm{Li}: \mathrm{ZnO}$ film spin coated on ITO glass from sol-gel solution [26] as well for polypyrrole film electrodeposited on ITO [27]. In this last work both the shrinkage and the drying of the polymer were discarded as possible source of wrinkles formation. According to our results these morphological features are rather independent from the method of growth of polymers so that the wrinkles seem originated during the growth process at the oxide/polymer interface and affected mainly by the polymer-oxide interaction governing the adhesion process. By comparing the morphological features of the polymer after doping and de-doping no appreciable differ- 


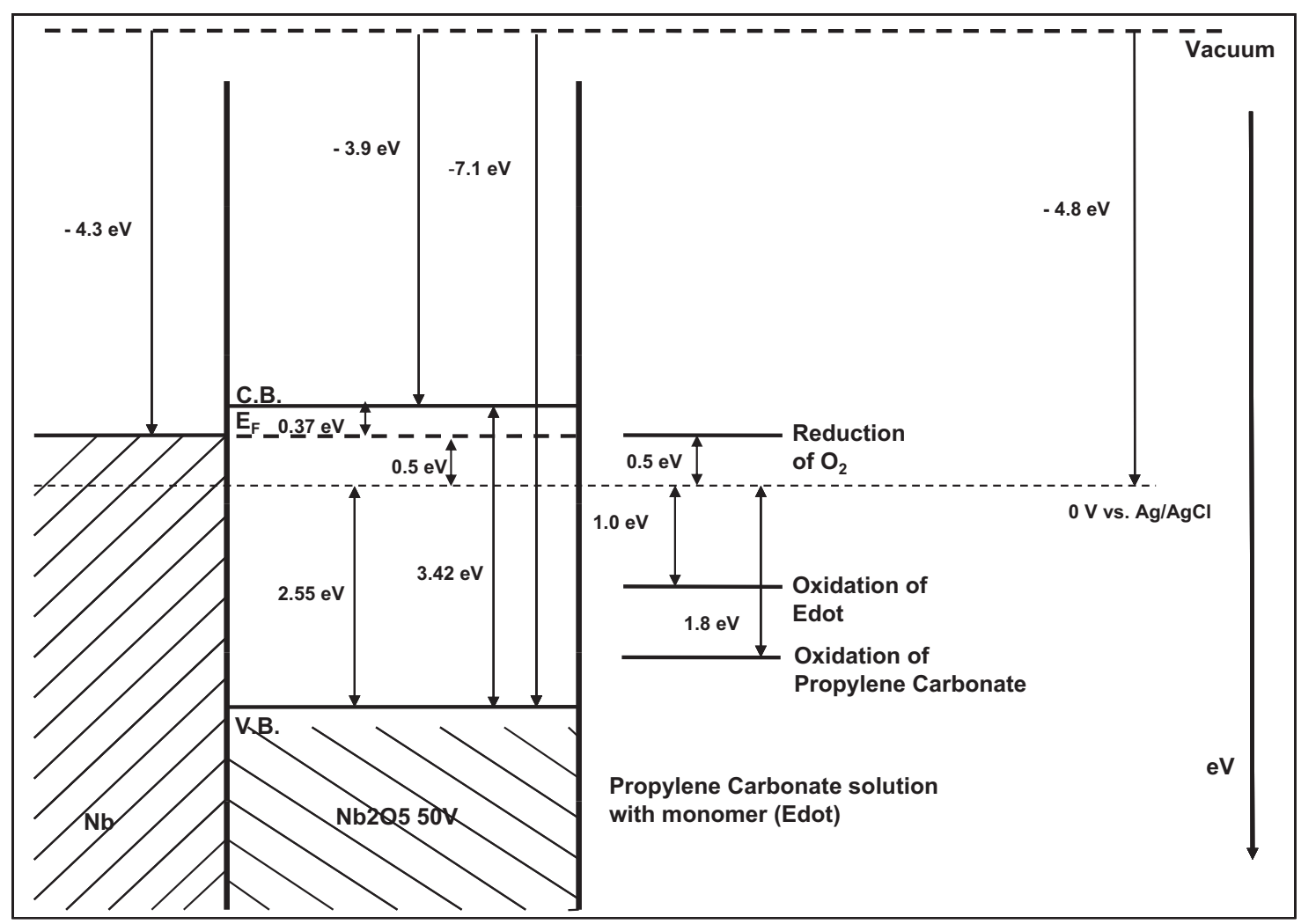

Fig. 8. Schematic picture of the energetic levels at the $\mathrm{Nb} / \mathrm{Nb}_{2} \mathrm{O}_{5} /$ organic solution (containing Edot) interface. The reported oxygen reduction potential is from Ref. [11].
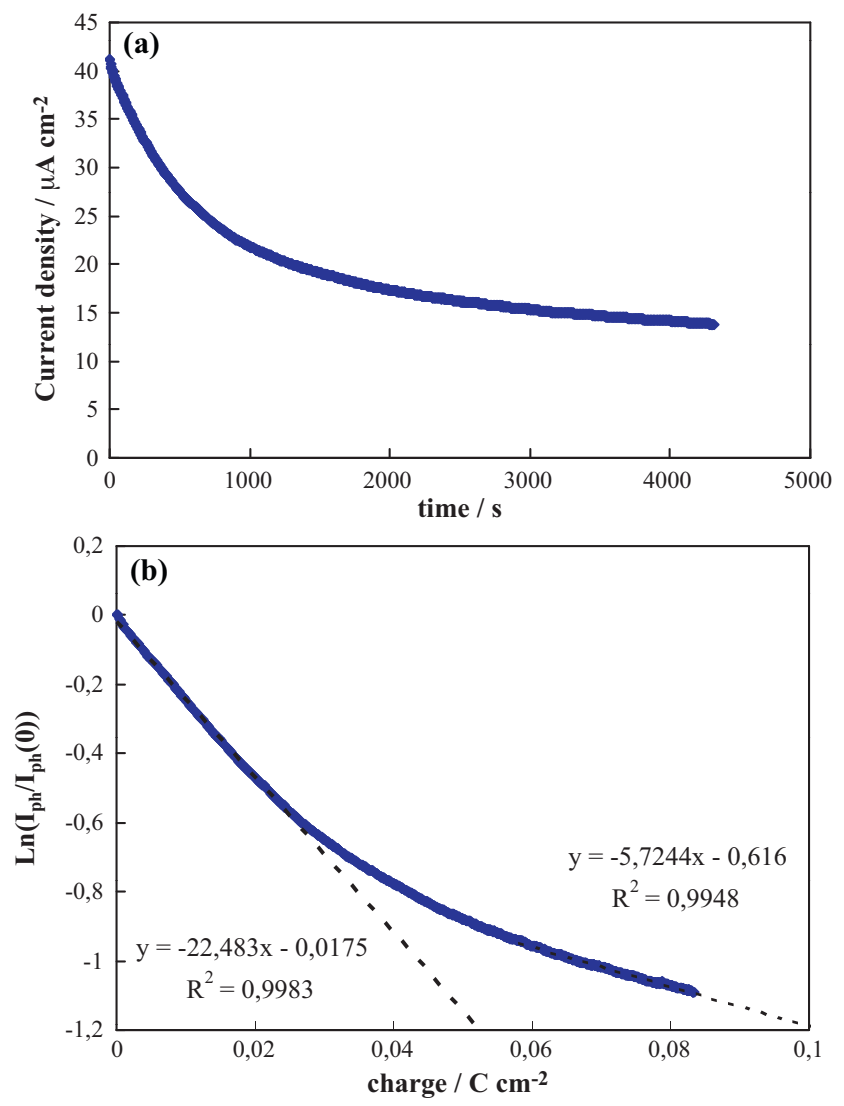

Fig. 9. (a) Current density vs time curve recorded by polarizing the electrode $\left(\mathrm{Nb}_{2} \mathrm{O}_{5}\right)$ at $8 \mathrm{~V}(\mathrm{Ag} / \mathrm{AgCl})$ in $0.1 \mathrm{M} \mathrm{LiClO}_{4}$ propylene carbonate solution containing $0.04 \mathrm{M}$ Edot under irradiation at constant wavelength $(\lambda=320 \mathrm{~nm})$. (b) Elaboration relating to the curve of (a) to determinate the $\alpha$ coefficient of PEDOT. ences were evidenced, thus suggesting that the morphology of the polymer is not strongly influenced by the anions incorporation.

At higher magnification an irregular morphology appears between the ridges on the solution-side polymer but less porous than that shown by the electrochemically grown polymer after the same amount of circulated charge (compare Figs. 2c and 10b). A very uniform surface was observed on oxide side polymer formed by the cohesion of small polymer islands (Fig. 10c).

In Fig 10d we also report the SEM micrograph relating to the cross section of the photoelectrochemically grown polymer. By averaging the measured thickness on several areas of the same sample and on several samples, it was possible to estimate the efficiency of the process, as described in Section 3.1, very close to that estimated for electrochemically grown polymer. In spite of the rough estimate, the efficiency is very close to that previously reported for the photoelectrochemical synthesis of polypyrrole on tantalum oxide in MeCN solution.

The presence of a PEDOT layer in its metallic state adherent to the surface of the anodic film does not modify appreciably the shape of the anodic photocurrent spectra with respect to those recorded in the absence of polymer (see Fig. 6a), neither the value of measured optical band gap (see Fig. 6c). In fact its value $(3.39 \mathrm{eV})$ is coincident with that reported in Fig. $6 \mathrm{~b}$ thus suggesting that the measured photocurrent is sustained by the photo-holes generated in the valence band of the niobium oxide. The growth of polymer film partially absorbing the incident light accounts for the decreasing photocurrent intensity recorded under constant anodic polarization (see Fig. 9a). The formation of a metallic-like p-type degenerated semiconductor is suggested owing to the anion doping process described in Eq. (5c).

By polarizing the oxide/PEDOT/solution interface under cathodic potential, the de-doping process allows to evidence the p-type character of the polymer. In Fig. 11a we report the cathodic photocurrent spectrum of $\mathrm{Nb}_{2} \mathrm{O}_{5} / \mathrm{PEDOT} /$ solution junc- 
(a)

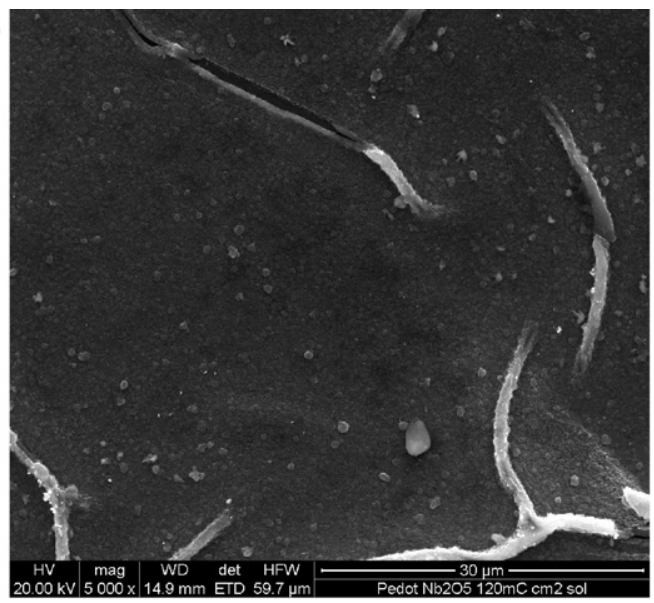

(c)

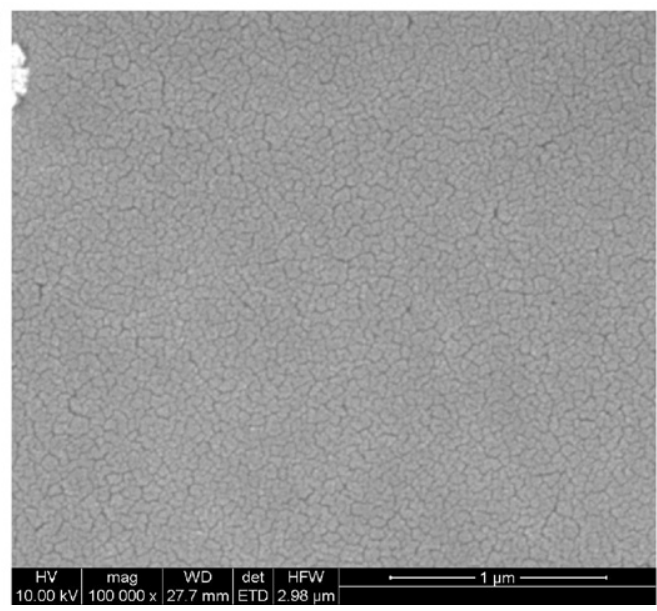

(b)

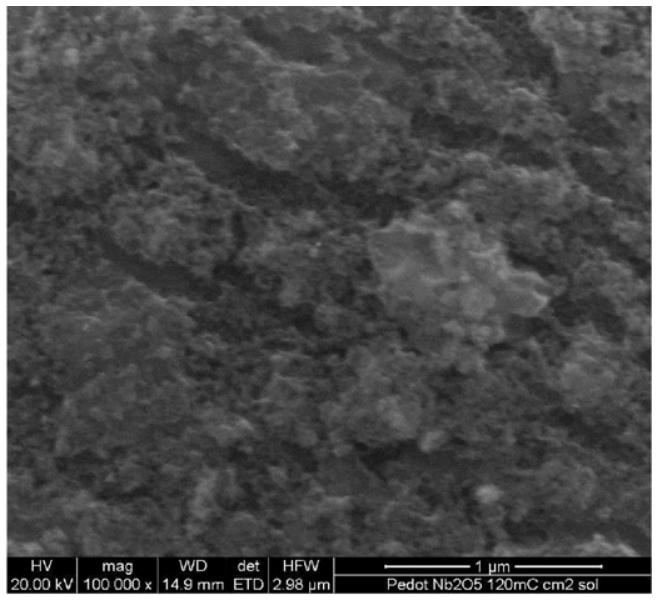

(d)

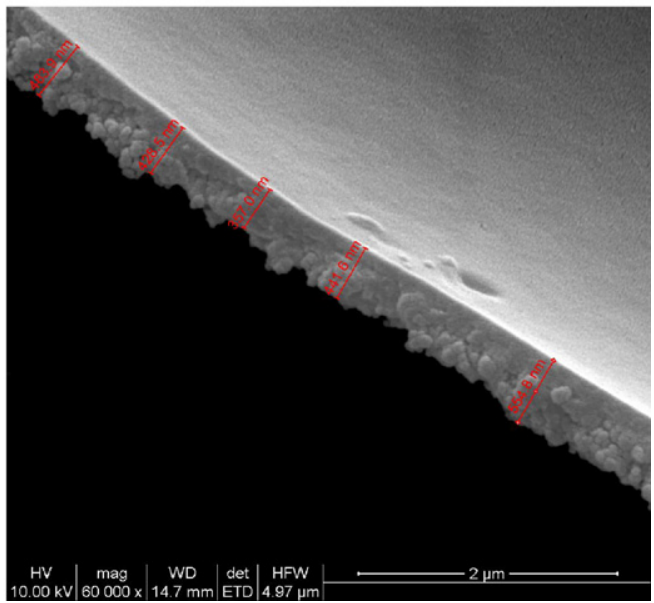

Fig. 10. SEM micrographs relating to PEDOT grown photoelectrochemically $(\lambda=320 \mathrm{~nm})$ at $E=8 \mathrm{~V}(\mathrm{Ag} / \mathrm{AgCl})$ on $\mathrm{Nb}_{2} \mathrm{O}_{5}$ after circulation of $120 \mathrm{mC} \mathrm{cm}^{-2}$. (a and $\left.\mathrm{b}\right)$ Solution-side surface morphologies, (c) oxide side morphology and (d) cross section of polymer.
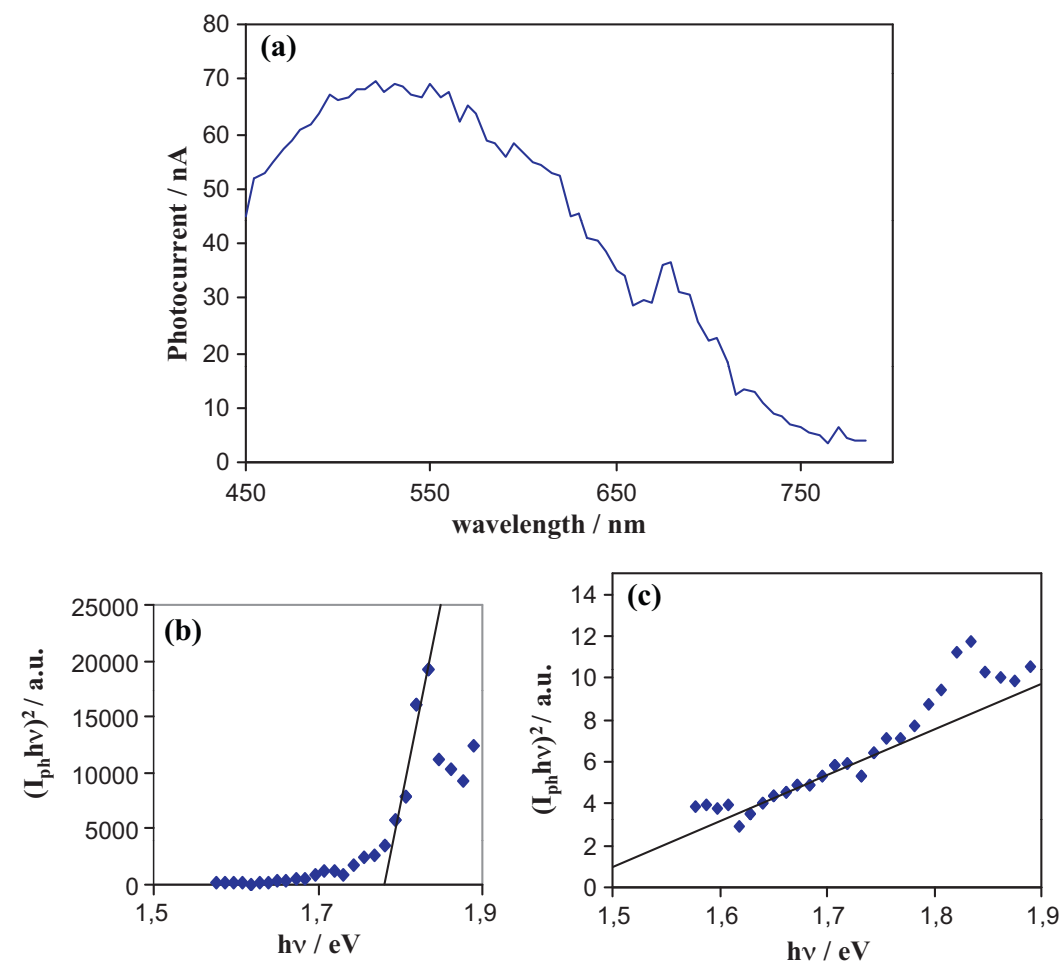

Fig. 11. (a) Raw cathodic photocurrent spectrum relating to PEDOT photoelectrochemically grown after circulation of $120 \mathrm{mC} \mathrm{cm}^{-2}$ on oxide $\left(\mathrm{Nb}_{2} \mathrm{O}_{5}\right)$ electrode, recorded by polarizing the $\mathrm{Nb} / \mathrm{Nb}_{2} \mathrm{O}_{5} / \mathrm{PEDOT}$ interface in $0.1 \mathrm{M} \mathrm{LiClO}_{4}$ propylene carbonate at $E=-2 \mathrm{~V}$ (Ag/AgCl). Band gap estimate by assuming (b) direct and (c) non-direct optical transitions. 


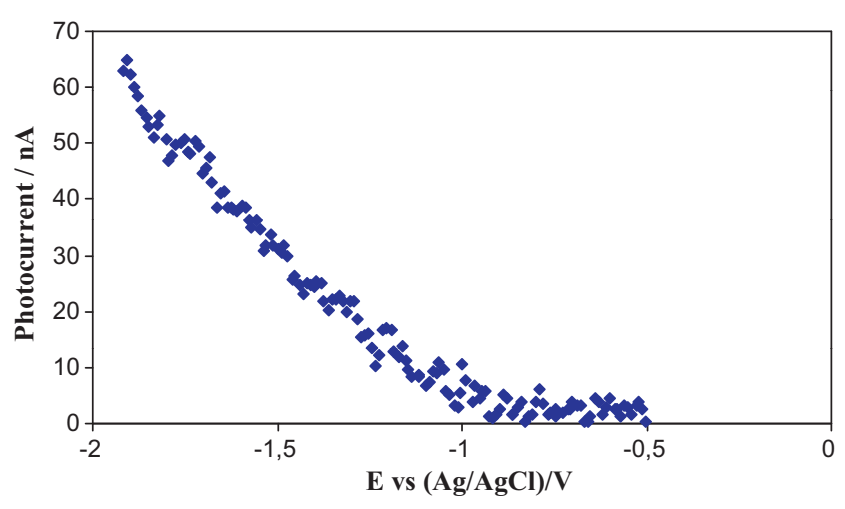

Fig. 12. Photocurrent vs potential curve relating to PEDOT film photoelectrochemically grown after circulation of $120 \mathrm{mC} \mathrm{cm}^{-2}$ on oxide $\left(\mathrm{Nb}_{2} \mathrm{O}_{5}\right)$ electrode, recorded by irradiating the $\mathrm{Nb} / \mathrm{Nb}_{2} \mathrm{O}_{5} /$ Pedot/Solution interface in $0.1 \mathrm{M} \mathrm{LiClO}_{4}$ propylene carbonate at $500 \mathrm{~nm}$.

tion recorded at $-2 \mathrm{~V}$ vs $\mathrm{Ag} / \mathrm{AgCl}$. A direct optical transition at $1.78 \mathrm{eV}$ (Fig. 11b) and an indirect one at around $1.46 \mathrm{eV}$ (Fig. 11c) were determined; both values being very close to those estimated for PEDOT grown on gold electrode. In Fig. 12 we report the photocurrent vs potential curve recorded at $500 \mathrm{~nm}$ in $0.1 \mathrm{M} \mathrm{LiClO}_{4} \mathrm{PC}$ electrolyte relating to the polymeric film grown on Niobium oxide. From this figure it is possible to see that the potential of zero photocurrent is more cathodic than those measured for PEDOT grown on gold electrode; probably owing to an additional potential drop inside the niobium oxide absent for conducting substrate like gold.

\section{Conclusions}

A photoelectrochemical method for the electropolymerization of EDOT on wide band gap anodic $\mathrm{Nb}_{2} \mathrm{O}_{5}$ was successfully realized. A SEM characterization was performed on both electrochemically and photoelectrochemically grown polymers for evidencing their morphological features.

A photoelectrochemical investigation was performed in order to get information on the energetics of the $\mathrm{Nb} / \mathrm{Nb}_{2} \mathrm{O}_{5} /$ electrolyte interface as well as on the solid state properties (band gap, flat band potential, conductivity type) of the polymer. The photoelectrochemical properties of PEDOT prepared on $\mathrm{Nb}_{2} \mathrm{O}_{5}$ were compared with those of the polymer electrochemically grown on gold.

The described method allowing the polymerization of conducting polymers in physical and electric contact with the wide band gap material can play an important role for the fabrication of large area metal/oxide/conducting polymer composites not only for solid state capacitors but also, more generally, for organic/inorganic electronic devices.

\section{Acknowledgments}

This work is sponsored by USAITC-A under contract $\mathrm{N}$. noW911NF-09-10461 and University of Palermo. The authors want to acknowledge Prof. H. Habazaki (Graduate School of Engineering, Hokkaido University, Japan) for providing sputtered Nb samples.

\section{References}

[1] P. Kathirgamanathan, S. Ravichandran, Synth. Met. 74 (1995) 165.

[2] Y. Kudoh, K. Akami, Y. Matsuya, Synth. Met. 102 (1999) 973.

[3] K. Ueno, L. Dominey, H. Uchi, R.S. Alwitt, J. Surf. Finish. Soc. Jpn. 60 (2009) 179.

[4] F. Di Quarto, V. Figà, P. Bocchetta, M. Santamaria, Electrochem. Solid State Lett. 10 (2007) H305.

[5] F. Di Franco, P. Bocchetta, M. Mosca, C. Calì, M. Santamaria, F. Di Quarto, submitted for publication.

[6] (a) R. Noufi, A.J. Franck, A.J. Nozick, J. Am. Chem. Soc. 103 (1981) 1849; (b) G. Cooper, R. Noufi, A.J. Frank, A.J. Nozik, Nature (London) 295 (1982) 578.

[7] B.L. Funt, S.-R. Tan, J. Polym. Sci. A (Polym. Chem.) 22 (1984) 605; P.V. Kamat, R.V. Todesco, J. Polym. Sci. A (Polym. Chem.) 25 (1987) 1035; A. Yildiz, A. Sobczynski, A.J. Bard, A. Campion, M.A. Fox, T.E. Mallouk, S.E. Webber, J.M. White, Langmuir 5 (1989) 148;

M.A. Fox, K.L. Worthen, Chem. Mater. 3 (1991) 253.

[8] Y.T. Ravikiran, M.T. Lagare, M. Sairam, N.N. Mallikarjuna, B. Sreedhar, S. Manohar, A.G. MacDiarmid, T.M. Aminabhavi, Synth. Met. 156 (2006) 1139.

[9] H. Habazaki, T. Ogasawara, K. Fushimi, K. Shimizu, S. Nagata, T. Izumi, P. Skeldon, G.E. Thompson, Electrochim. Acta 53 (2008) 8203.

[10] F. La Mantia, M. Santamaria, F. Di Quarto, H. Habazaki, J. Electrochem. Soc. 157 (2010) C258.

[11] F. Di Quarto, F. La Mantia, M. Santamaria, in: S.-I. Pyun, Jong-Won Lee (Eds.), Modern Aspects of Electrochemistry, vol. 46, Springer, New York, 2009, pp. 231-316 (Chapter 4).

[12] M. Dietrich, J. Heinze, G. Heywang, F. Jonas, J. Electroanal. Chem. 369 (1994) 87.

[13] A.J. Bard, L.R. Faulkner, Electrochemical Methods: Fundamentals and Applications, John Wiley \& Sons, 2000.

[14] B.L. Funt, A.F. Diaz, Organic Electrochemistry: An Introduction and a Guide, Marcel Dekker, New York, 1991, p. 1337.

[15] E.M. Genies, G. Bidan, A.F. Diaz, J. Electroanal. Chem. 149 (1983) 101.

[16] H. Randriamahazaka, V. Noel, C. Chevrot, J. Electroanal. Chem. 472 (1999) 103.

[17] A.L. Melato, A.S. Viana, L.M. Abrantes, Electrochim. Acta 54 (2008) 590.

[18] R.J. Waltman, J. Bargon, A.F. Diaz, J. Phys. Chem. 87 (1983) 1463.

[19] S. Patra, K. Barai, N. Munichandraiah, Synth. Met. 158 (2008) 430.

[20] R. Kiefer, G.A. Bowmaker, R.P. Cooney, P.A. Kilmartin, J. Travas-Sejdic, Electrochim. Acta 53 (2008) 2593.

[21] N.F. Mott, E.A. Davis, Electronic Processes in Non-crystalline Materials, 2nd ed. Clarendon Press, Oxford, 1979.

[22] M. Kertesz, C.H. Choi, S. Yang, Chem. Rev. 105 (2005) 3448.

[23] S.S. Zade, M. Bendikov, Org. Lett. 8 (2006) 5243.

[24] Z.V. Vardeny, X. Wei, in: T.E. Skotheim, R.L. Elsenbauner, J.R. Reynolds (Eds.) Handbook of Conducting Polymers, 2nd ed., Marcell Decker, New York, 1998, p. 639.

[25] E. McCafferty, J. Electrochem. Soc. 146 (1999) 2863.

[26] M.T. Lloyd, Y.-J. Lee, R.J. Davis, E. Fang, R.M. Fleming, J.W.P. Hsu, R.J. Kline, M.F. Toney, J. Phys. Chem. Lett. 113 (2009) 17608.

[27] M.J. Miles, W.T. Smith, J.S. Shapiro, Polymer 41 (2000) 3349. 